\title{
De Novo Practice of Oral and Maxillofacial Surgery
}

\author{
Srinivas Gosla Reddy and Avni Pandey Acharya
}

\subsection{Introduction}

The exhilarating and exciting emotion of starting your own practice can also be a daunting experience to a freshly passed out maxillofacial surgeon. Student loans taken during the course of one's studies also play a significant role in determining one's ability to take on any additional financial burden.

As oral and Maxillofacial surgery is a bridge between medicine and dentistry, there is a continual national debate regarding the need to pursue a dual degree. The option to pursue a condensed medical degree as part of the current syllabus is still not available in India. Thus, new residents should always strive to do additional training [residency, fellowship and diplomas] in their fields of interest to expand their expertise prior to starting their own set-ups [1]. It is a well-known fact that it is easier to gain knowledge and skills during the starting of one's career rather than later in life. The goal is to aim high by keeping one's feet grounded in the soil of academics.

The fire of determination and passion should always be kept alive in order to truly succeed and excel in our field. The truly successful surgeon is the one who has thrived against all the odds and taken advantage of every opportunity that has come his or her way. This chapter aims to guide the freshly passed out maxillofacial surgeon regarding further avenues of learning and about the establishment and expansion of one's surgical practice.

\subsection{Professional Skill and Learning}

For the freshly passed out maxillofacial surgeon, the option of acquiring financial stability always appears alluring. However, it is a well-known fact that enhanced surgical skills

S. G. Reddy $(\bowtie) \cdot$ A. P. Acharya

GSR Institute of Cranio-maxillofacial \& Facial Plastic Surgery, Hyderabad, Telangana, India and strong academic knowledge cannot be traded for the financial gains obtained by prematurely starting one's surgical practice. Thus, it is always advisable to pursue additional training in the form of a fellowship, residency or diploma in one's area of interests $[2,3]$. This trend will help the surgeon establish a niche practice where they specialize in a particular domain of oral and maxillofacial surgery, which eventually leads to improved surgical results and credibility for our profession. This kind of surgical practice will also help to create an edge over the plastic surgeon and the otolaryngologist and establish a distinguishable specialty offering an unequivocal service to patients. Despite the prevailing circumstances governing one's decision to enter practice immediately or continue training, everyone will eventually contribute to the OMFS field with their skills and knowledge.

Laskin [4] made an organized attempt to tackle this problem by dividing the scope of oral and maxillofacial surgery into three categories: areas of expertise, competence, and familiarity. To be addressed as an oral and maxillofacial surgeon, one needs to include the areas of expertise and competence in their work profile.

- Areas of expertise include oral pathology/oral medicine, dentoalveolar surgery, implantology, pre-prosthetic surgery, and maxillofacial traumatology.

- Areas of competence involve orthognathic surgery, temporomandibular joint surgery, and local reconstructive surgery.

- Areas of familiarity are cleft lip and palate surgery, regional reconstructive surgery, oncologic surgery, craniofacial surgery, and cosmetic surgery.

The first step in learning a skill is to know how a skill is learned. Educationists have constructed many models attempting to outline the learning process. The most widely accepted was first documented by Noel Bunch and was subsequently re-worked by Abraham Maslow (Figs. 43.1 and 
43.2). In the beginning, a student is in the 'unconsciously incompetent' phase. An undergraduate dental student in their third year would have no idea about administering local anaesthesia. After working on the skill for some time, they move on to the 'consciously incompetent' phase. Here, they have attempted different ways of anaesthetizing teeth and are now keenly aware of the various ways to give local anaesthesia along with their shortcomings in certain regional nerve blocks.

Most of our trainees will arrive somewhere between these two steps of knowing what they can and cannot perform. Educators must help them overcome their limitations. Once they are aware of their shortcomings, they can actively

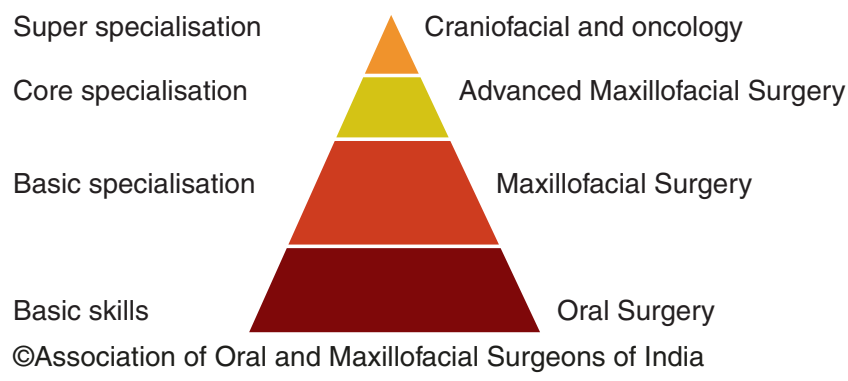

Fig. 43.1 Gradation of maxillofacial surgery and importance of super specialization begin to correct them. With practice and appropriate teaching, they move to the third level of being 'consciously competent'. Here, the trainee can perform every step of local anaesthesia along with variations of different techniques. However, the steps require focus and assiduousness. Now, he or she would be considered as a competent surgeon who can practice independently although lacking in instinctiveness. As learning advances, with years of handwork and practice, they will reach to the concluding stage, 'unconsciously competent'. Now the local anaesthesia can be given while listening to music or talking to patients or colleagues [5].

The obstacle to a meticulous 'ability preparation' is that most of our instructors perform numerous components at an unknown and advanced skilled dimension, while the students are frequently unmindful of numerous components of what they have to learn. The individuals who have overlooked the subtleties of an expertise are entrusted with showing people who don't know about what abilities they are unequipped for performing. The initial step for an ace instructor is to perceive that the educator and understudy live at inverse finishes of the authority. Perception, readiness, practice and tolerance are the key components of learning in any skill [6].

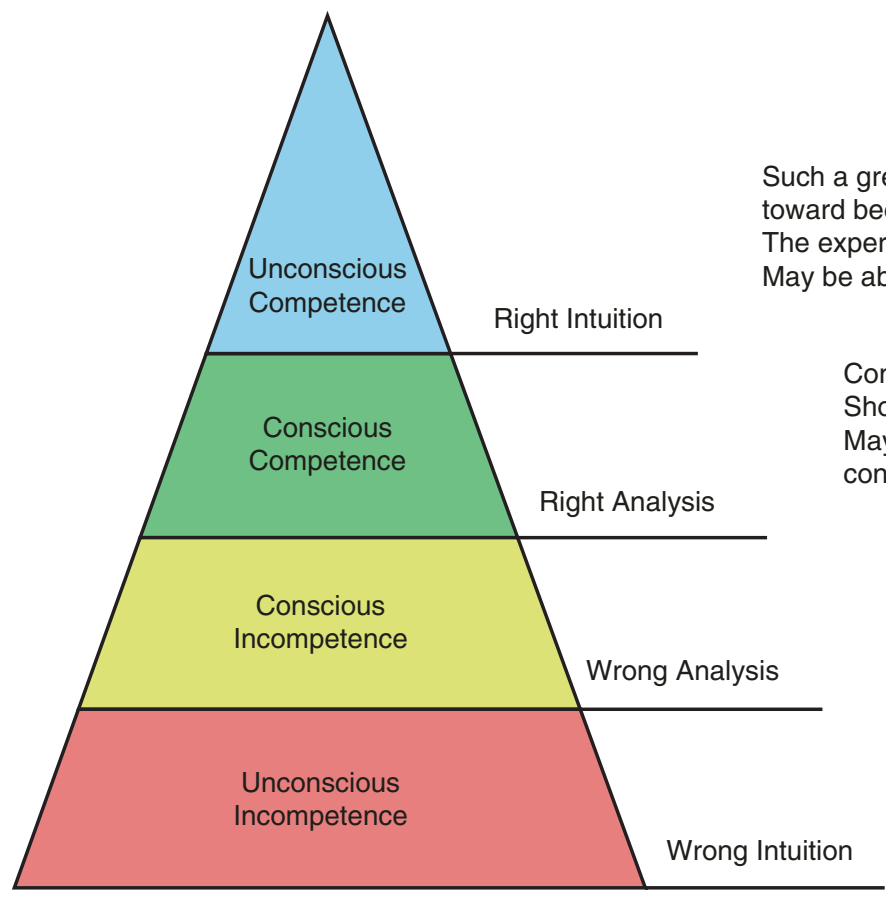

Hierarchy of Competence

(C)Association of Oral and Maxillofacial Surgeons of India
Does not comprehend or realize how to accomplish something

Does not perceive the shortfall or value of the ability. Perceive their own ineptitude and estimation of the new expertise

Does not comprehend or realize how to accomplish something,

Hierarchy of Competence

Recognizes the shortage, just as the estimation of another ability intending to the shortfall.

Creation of slip-ups can be basic to the learning procedure at this stage

Fig. 43.2 Competence hierarchy 


\subsubsection{Kolb's Learning Cycle [7]}

David Kolb is renowned in educational circles for his Learning Style Inventory. In Kolb's speculation, the drive for the headway of new thoughts is given by new experiences. "Learning is the technique whereby data is made through the difference in comprehension" [7]. Kolb's experiential learning style theory is conventionally addressed by a four-stage learning cycle in which the understudy contacts all of the bases (Fig. 43.3). Along these lines, everyone responds to and needs the improvement of a wide scope of learning styles.

Here are brief depictions of the four Kolb learning styles:

\section{- Diverging (feeling and watching-CE/RO)}

These individuals can take a gander at things from alternate points of view. They are touchy. They want to observe as opposed to doing, tending to accumulate data and use creative ability to tackle issues. They are best at reviewing solid circumstances from unique perspectives.

Kolb called this style 'separating' in light of the fact that these individuals perform better in circumstances that require thoughts, for instance, conceptualizing. Individuals with a wandering learning style have wide social premiums and like to assemble data.

They are keen individuals, will in general be inventive and enthusiastic, and will be solid in expressions of the human experience. Individuals with the veering style like to work in gatherings, to tune in with a receptive outlook and to get individual criticism.

\section{- Assimilating (watching and thinking-AC/RO}

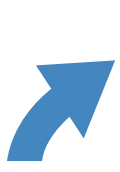

Active

Experimentation

(planning / trying out

what you have learned)

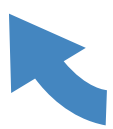

Abstract

Conceptualisation

(concluding / learning

from the experience)

CAssociation of Oral and Maxillofacial Surgeons of India

Fig. 43.3 Kolb's Experiential learning cycle
The Assimilating learning inclination is for a compact, sensible methodology. These individuals require clear clarification as opposed to pragmatic chance. They exceed expectations at seeing wide-going data and sorting out it in a reasonable coherent configuration.

This learning style is essential for viability in data and science vocations. In formal learning circumstances, individuals with this style incline toward readings, addresses, investigating diagnostic models, and need room to thoroughly consider things.

\section{- Converging (doing and thinking-AC/AE)}

Individuals with this combining learning style can tackle issues and will utilize their figuring out ability to discover answers for reasonable issues. They lean toward specialized assignments and are less worried about individuals and relational angles.

Individuals with a combining learning style are more pulled into specialized errands and issues than social or relational issues. A meeting learning style empowers expert and innovation capacities. Individuals with a meeting style like to try different things with new thoughts, to recreate, and to work with handy applications.

\section{- Accommodating (doing and feeling-CE/AE)}

The Accommodating learning style is 'hands-on' and depends on instinct as opposed to rationale. These individuals utilize other individuals' examination and want to take a viable, experiential methodology. They are pulled in to new difficulties and encounters. They usually follow up on 'gut' nature as opposed to sensible examination.

Individuals with an obliging learning style will in general depend on others for data than complete their own examination. This learning style is common inside the all-inclusive community. To become familiar with specific, careful abilities, an understudy needs to go intensively through every one of the styles of learning. First, we have to observe, think and feel pursued by experimentation on models to learn the aptitude to do medical procedure on humans.

\subsubsection{Transformative Learning Way}

Transformative learning is the procedure by which we digest and decipher data based on our own encounters to date, to deal with ace Surgical aptitudes. This can be seen in a case of a boss helping a careful student with his or her first case. One of the key issues is for the chief to be accessible if for no other explanation other than to counsel, whenever required, and guarantee that things go easily. Grown-up students need to realize that they have the director's certainty and support 
and that they will be permitted to extend their range of abilities to attempt to take care of any issues they may experience, before the chief strides in.

The following enquiries of destinations and points can give understanding into the learner's self-appraisal capacity or trainee's self-assessment:

- Pre-employable appraisal or Pre-operative assessment

- Discourse of case, history, examination and examinations to date.

- Discourse of the means of the activity and who will attempt which part-the director ought not to set suddenly exclusive requirements, just what is sensible to accomplish for the dimension of the student.

- Conceivable complexities and their goals

- Armamentarium.

- Consent

- Break process

\subsubsection{Intra-operative Educating}

- The student endeavours to pursue the pre-operative plan and, if there is a deviation, guarantees to take assent from the supervisor.

- The supervisor controls through the central specialized advances and focuses on technical steps and gives assertion for leading following the next stage, simply after fruitful fulfilment of past advances.

- The teacher gives prompt input on what is being progressed admirably and what should be possible in an unexpected way.

- The chief considers enabling the student to accomplish more on the off chance that they are advancing admirably and exhorts them in like manner.

The teacher must attempt to 'dominate', if important to help the patient yet this positively doesn't imply that boss should hinder in each progression and make the student uncertain.

\section{Post-operative questioning}

This can begin to happen as the student is concluding the case; however, a few learners may discover this diverting, which may hamper their execution.

The chief should plan to question in a peaceful domain.

- Ask the student how they think they went, invigorate reflection and show general tenets; help them survey their execution; investigate ways they can set a few objectives to help address insufficiencies

- Provide explicit instances of how the student could have performed better. An administrator may figure the learner progressed nicely, yet on the off chance that they don't convey, the student may feel that some perspective was not progressed admirably. Strong correspondence is critical [8].

\subsection{Career Goals}

Oral and maxillofacial surgery gives a wide range of alternatives from a conventional private minor oral surgery practice to specialist maxillofacial surgery in trauma, temporomandibular surgeries, orthognathic surgeries, implantology, oncology, aesthetic surgery and cleft and craniofacial surgery [9]. The following are the alternatives, which can be taken by a newly passed oral and maxillofacial surgeon:

- Associateship-The possibility of associateship with an officially settled practice is by all accounts extremely appealing. By joining a specialist set-up, one stays away from the numerous costs and unpleasant circumstances involved in setting up one's own practice. However, one should make sure to join the right specialist practice. There is a lot of contrast between a specialist that genuinely needs a partner and a specialist that may need a partner for increasingly narrow-minded reasons. The practice may not have enough volume to support two specialists and the senior associate may. In this situation, the new specialist may be in charge of creating the new referrals. This can be a troublesome circumstance. In addition, one may anticipate that as the new associate one should take an excessive measure of call, see all patients with insurance formalities and not take an interest in the 'great cases'. Additionally, the desires of the senior associate might be farfetched and a lot of additional fault may be put on the new junior associate. Before getting engaged with any of the associateship, the term and conditions ought to be clear in the pre-legally binding stage [10].

- Scholastics and Research-Teaching is one of the alternatives for a specialist who has the enthusiasm to educate the new batch of upcoming surgeons. It is one of the best ways to remain connected with your field. There are many institutes looking for youthful surgeons with a keen interest in academics, research and administrations [11].

- Organization-Being a manager includes leading, managing, overseeing and supporting health care departments or associations to accomplish their pre-set goals. With the opening of a several corporate hospitals, administrators with a medical background are most desirable for such roles. The size, intricacy and mission of various healthcare organizations (hospital systems, academic medical centres, practice groups, insurance companies) require assistance from experienced specialists with fluctuating roles [12]. 
- De novo Practice-Opening one's own OMFS office from the ground up is an extremely tough task that is not for the weak hearted. It has been rightly said the war field ought not be entered without a weapon and thus one need to be confident in their surgical skills and also have a basic understanding of the administration involved with running one's own practice [10].

\subsection{De Novo Practice}

\subsubsection{Requirements}

- Surgical Skills: Never accept surgery as an easygoing endeavour and always keep the patient's prosperity over any of your own advantages. It is important to develop surgical skills early on in one's career as it is these skills that will carry you forward throughout life. However, one should also make an effort to get the right opportunity

- Site or place of your practice: Selection of the place where you will set up your centre is the first and most basic decision that one comes across. Choosing a location that has a geographic advantage [as in easily accessible via adequate public and private transport] and has an adequate population to support your practice is essential. Demand and supply also needs be considered when choosing your location. Too many competing specialists in the vicinity will definitely make attracting patients difficult. However, it must be said that the eventual fate of a practice depends on the surgical skills and services offered by the surgeon in charge. Lastly, the spot ought to be close to the living arrangement of the surgeon in case of a medical emergency [13].

- Accounts or Finances: It is prudent to begin a project of such magnitude with your financial capacity in mind. Very few specialists manage to acquire stipends during their residency programs and hence are not well acquainted with handling funds. One should avoid large and unnecessary expenses in the beginning. However, this does not mean that one should skip on the basic requirements for starting a well-equipped practice. Expansion, modernizing and incorporation of advanced technology into the practice must be kept as a long-term step wise plan. The computations of property expenses [rent/lease/ loan], staff salaries, equipment costs, sterilization and biomedical waste management ought to be dependably considered in evaluating the finances [14].

- Framework: The rooms required in an OMFS workspace are as follows: reception room, business zone, financial zone, exams rooms, operatories, $\mathrm{x}$-ray zones, research centre space, staff lounge, specialist's private office, restrooms, medicinal gas space, mechanical space, sterilization space, recovery space and storage space [10].
- Marketing strategy: Health care associations actualize business techniques through projects and administrations, and achievement relies upon program structure and execution. Beginning a business adventure without an arrangement is out and out welcoming a fiasco and human services is no exemption for this standard. Since we are specialist co-ops, we ought to dependably remember that this field is certifiably not a "high pay" creating field except if we are managing corporate divisions. That is the reason why practical objectives ought to be set to keep ourselves as well as other people away from the rat race of cash. This positively doesn't imply that you ought not dream about a sensible way of life.

\subsubsection{Types of Practice}

There are four different ways by which medical practices can be organized:

(a) Sole Proprietor-This is for the specialist who already has a foundation of maxillofacial surgical or other medical service organizations running in the family. The choice appears to be practical for the surgeon who has full control of his financial assets and is as of now experienced in the field [15].

(b) Organization or associateship - If you have fellow medicos who are of the same or diverse fields and are prepared to create a combined practice with you, then it is the most reasonable choice. Always scrutinize your colleagues before entering into such arrangements. The success of this arrangement relies upon mutual trust for each other. It is also necessary to discuss all the terms and conditions [expenses and division of profits] before entering such an arrangement.

Additionally, you can work under the umbrella of some settled specialist and eventually move toward becoming a partner in the not-so-distant future [15].

(c) Corporate segment. Joining corporate hospitals or chains is also an alternative. The hustles of marketing, equipment, and location can be obliterated. However, corporate hospitals today are keen on hiring well-settled specialists as patients are hesitant being treated by novice surgeons [15].

(d) Trust or NGOs-These organizations are created to help unaffording individuals for treatment. One cannot expect great monetary benefits from a trust or NGO. However, there is a feeling of fulfilment of helping other people. There are a few associations in and outside India, which raise funds for such organizations. A point worth noting is that there are numerous specialists who are working free of charge under such associations while simultaneously obtaining their standard pay elsewhere [15]. 


\subsubsection{Qualities Needed}

\subsubsection{Strategic Planning}

Due to the contingent nature of the decision of essential structure be it sole owner or in affiliation, Strategic arranging is required. It is a definite methodical report demonstrating the manner in which it intends to advance from its present circumstance to the ideal future situation [16].

The SP procedure is isolated into progressive stages. The writing gives diverse names to unmistakable stages yet we are adopting established strategy, distinguishing five values simultaneously. The Mission, Vision and Values ought to be institutionalized amid the underlying stages.

- Mission

- This mission characterizes the general motivation behind the association, the objective customers, the administrations offered, its distinctive highlights, the geological territory in which the centre works, and occasionally the manner in which it works (quality, morals, productivity, and so forth.).

- Vision

- The vision displays the future picture. The substance of the vision ought to uncover what the human services association explicitly tries to be later on.

- Qualities

- Qualities are the arrangement of standards, rules and social viewpoints administering the Hospital Organization (HO) and deciding their institutional conduct. They comprise the association's moral code that gives it its 'spirit' and 'character'. These qualities foresee a particular reaction by the $\mathrm{HO}$ when a circumstance emerges that must be quickly settled.

\subsubsection{Technique Formulation}

The accompanying five phases ought to be considered

- First Stage: Analysing the External Environment

- This examination generates data on those difficult to change external variables that can affect the association. This involves patients and contenders.

- Patients: The place that you will eventually set up should have a geographic advantage with the right patient demographic. All too often, a specialist will begin their facility in a distant, underdeveloped and immature zone due to the dread of rivalry. It is a well-known fact that a specialist practice survives on referrals and not only on walk-in patients.

- Contenders: Good work and identity are significant in keeping an edge over your rivals. Endeavour to build up your individual character, as far as work and morals are concerned, should be made.
- Second Stage: Analysing the Internal Environment

- This investigation generates data on everything pertinent that has/can and is happening inside the set-up. This investigation centres around three distinct angles:

- Resources: It incorporates individuals, monetary spending plans, consumable and non-consumable supplies and their level of obsolescence.

- Licensure-Legal parts of drug store, radiations, and different licenses with respect to specific region ought to be taken already relying upon the standards of the region.

- Analysis of clinical and research work, action and spending plan ought to dependably be kept aside [16].

\section{- Third Stage: The SWOT matrix}

- When the outside and inside examinations have been finished and coordinated, the vital arrangement directing gathering will have an abundance of thoughts regarding conceivable vital activities that could be tended to in the arrangement. Then, the issues distinguished in the examination are characterized into four classifications to comprehend what to do and in what request. This is the SWOT investigation, an abbreviation framed from qualities (S), shortcomings $(\mathrm{W})$, openings $(\mathrm{O})$ and dangers $(\mathrm{T})$, which orders the consequences of the examination.

- Every one of the outcomes, notwithstanding grouping them with SWOT criteria, can be weighted as far as significance or relative power (high, medium, and low;,+++ or +++ , and so on.). It permits the arranging group to build up a positioning, with the most vital components positioned in the principal position, situated to key priorities $[17,18]$.

\section{TOWS Matrix Analysis}

The TOWS Matrix is aimed at developing strategic options from an external-internal analysis. TOWS idea is firmly identified with SWOT investigation. Whereas SWOT Analysis starts with an internal analysis, the TOWS Matrix starts the other way around, with an external environment analysis; the threats and opportunities are examined first. As indicated by H. Weihrich (1982) [19], Dangers, Opportunities, Weaknesses, Strengths (of the association) ought to be examined in a specific order, as a critical thinking succession during the time spent on the procedure plan. To streamline, let's use TOWS examination in beginning an oral and maxillofacial medical procedure set-up:

Inner Strengths: The accompanying could be qualities of the endeavour:

- Proficient abilities of the head picked up by changed associations, confirmations and courses

- Focal Location of the set-up

- Access to demonstrated plan of action 
- Relationship with other dental and restorative fields to give all administrations under one rooftop

- The individual variables of the specialist like family foundation, past experience, unique intrigue, administrative and specialized abilities, self-assurance, inventiveness, creativity and eagerness to go for broke

\section{Inward Weaknesses}

- less familiarity with the field of Oral and maxillofacial medical procedure

- Constrained patient base if there should arise an occurrence of elite oral and maxillofacial practice

- Understanding paying limit

- Issue of staff wear out

Individual shortcomings (inside negative factors or challenge) like deficient abilities, terrible work propensities or attributes like poor relational abilities, poor systems administration, ineffectual authority characteristics, absence of specialized mastery, absence of IT information, absence of comprehension of statistical surveying, absence of promoting skill and so on because of which wrong choices are generally taken.

The following stage is the planning of TOWS 'Matrix of key' choices, which empowers determination of supportable, open door, simpler, and quantifiable results. 'Inward' are the shortcomings and qualities and 'outer' are the dangers and shortcomings. Four quadrants with various vital circumstances are created as pursued:

$\mathrm{S}$ - $\mathrm{O}$ - How can the organization employ the expertise of its own professionals to respond to the needs of centres? By partnering up, the organization can convince the institutions that there is enough capacity, knowledge and experience to train young people to independent professionals at all levels of surgery.

- SO circumstance-maxi-maxi system. This circumstance compares to the maxi-maxi methodology whereby it is conceivable to have solid extension and broadened advancement. In such cases, if the cost is utilized as to prepare individuals and keep them on minimal effort at first to give complete consideration by the prime specialist will prompt bringing down of beginning costs. Along these lines, more income is produced amid starting days just to have the capacity to rise as market pioneer.

$S$ - $T$ - How can the organization use its skilled staff to compete with cheaper workers employed by competitors? A smart approach for the organization would be to communicate to the outside world that their staff has accredited diplomas and that it's important for health care centres to comply with legal requirements and safety standards.
- ST circumstance-maxi-little system. The wellspring of troubles in development and improvement are ominous outer conditions (predominance of dangers) like a lot of swarming of good oral specialists in the zone, or patients paying limit is low, and so on. The procedure should utilize vast interior qualities in endeavour to defeat dangers from environment. The technique of reaching and catching patient ought to be connected through free camps, minimal effort medications contrasted with encompassing zones and catching exchange out specialists. On the off chance that the ability of the prime specialist is awesome, settle on troublesome cases left by different specialists with the dread of disappointment. In addition more up-to-date methods and medical procedures ought to be aced by the specialist in such cases.

$W$ - $O$ - How can partnerships with other centres help the organization to improve itself and put more effort into patient acquisition? By presenting itself as an accredited apprenticeship provider, the organization will put itself on the market again and its shows that adapt to changing times and wants to offer different kinds of treatments.

- This circumstance has more vulnerabilities-shortcomings, yet its condition gives more open doors like less number of oral specialists in the town and so forth. The procedure ought to incorporate the utilization of these chances while decreasing or amending shortcomings inside. Executing the arrangement step by step is required in such cases. The emphasis ought to be on improving the patient experience by great work by prime specialist, less staff and nearly not all that extravagant set-up amid introductory stage. Along these lines, cost cutting should be possible successfully without settling on the treatment plan. As the patient information and OPD increments, further advances can be taken for extension.

$W-T$-How can the organization better position itself in the market and thus reduce the threat posed by competitors? By presenting itself as an accredited apprenticeship provider, the organization can claim that they are a serious competitor and can possibly offer healthcare services by apprentices at reduced rates, with the work still being done by the prime specialists.

- WT circumstance-smaller than usual little methodology. This circumstance is without any advancement openings. It works in antagonistic situations, and its potential for change is little. It doesn't have huge qualities, which could withstand dangers. Scaled-down smaller-than-expected technique comes down to a negative rendition of the shut down or in idealistic circumstance-to take a stab at survival keeping in mind the 
desire of restoration. Advertising is the key in such cases alongside advancement of uncommon careful just as relational abilities of the prime specialist. Additionally, creating specialty brands are of significance as the abilities are not present with basic maxillofacial specialists. These brands include clefts, oral oncology, all out TMJ substitution and so on [17].

\section{- Fourth Stage: Strategic Alternatives}

- Equipped with this arrangement of recommendations, the vital arrangement controlling gathering starts a procedure, which orders them into characterized territories of activity. These zones of activity are additionally at the same time distinguished and named relying upon the kind of recommendations they contain [16].

- Fifth Stage: Strategic Areas and Objectives

- Now, it is prudent to adjust the procedure definition created, to check whether in reality a methodology exists by asking the accompanying inquiries:

- Does the plan give a key suggestion that will lead the setup to a truly remarkable position thinking about the challenge?

- Does it offer an incentive in an alternate manner?

- Are the key decisions that have been made substantial in the long haul?

On the off chance that there are negative answers, the detailing ought to be looked into to check whether, rather than shaping a key arrangement, an arrangement has been made with a progressively restricted scope [16].

\subsubsection{Operational Planning}

The point of operational arranging is to make the arrangement totally explicit, viable and unmistakable. The Operation destinations unite the accompanying attributes:

- They must have a fixed length, in every case under 1 year. Middle-of-the road objectives can be built up to be completed in various stages after some time.

- They ought to be evaluated. To follow their level of consummation, pointers that measure this are oftentimes required.

- They ought to challenge and keep the association in a condition of alarm so as to accomplish them.

- As a capability to the previous, the Operational goals ought to be feasible.

- Each objective must have an assigned individual in control, who truly has the ability to change the execution of the unit or subunit.

- Each Objective must have a cost doled out to its usage, with the end goal that the all-out expense of all the goals is equivalent to the absolute expense of the key arrangement.
- Each Objective must have the financing and different assets (staff time, gear and so forth.) important to accomplish the goals.

When all the OOs are detailed, the execution has to be incorporated with that of the others inside a course of events of activities that incorporates every one of them and gives an outline of the connections, timing and succession of errands, just as the joined endeavours that the $\mathrm{HO}$ needs to perform at each stage.

\subsubsection{Assessment of Results}

Auspicious evaluation of results ought to be done, which is dependent on development of number of patients, nature of administrations, nature of medical procedure, income age and work fulfilment. This should be possible by figuring the development charge. Arbitrary overviews on the web or discontent ought to be finished with the assistance of patients to keep up the pace of association and know the dimension of fulfilment of the patient with the health care providers, i.e. the head and the staffs. Likewise, number of patient waiting ought to dependably increase steadily for a feasible growth [16].

\subsubsection{Marketing Oral and Maxillofacial Surgery [20]}

- It is a must that both the specialist and the staff also show consideration for the patient's needs and have a humble attitude. This will go a great length in gaining the good will of the patient and word-of-mouth referrals.

- Utilizing online marketing tools through advertisement and social networking are slowly becoming a must for every new practice.

- Showcasing your work in study clubs, get-togethers and association conferences will also make fellow medicos aware about your abilities.

- You can publish in the neighbourhood newsletters through knowledgeable articles with respect to your field.

- Conducting free camps for check-ups with the neighbourhood non-profit associations can also help showcase your aptitudes.

\subsubsection{Staff Hiring}

The staff should be skilled in their work and maintain a humble and empathetic attitude. Always hire and maintain the correct staff

- Make clear what is expected of them through a detailed manual

- Train them to be focused in their specific roles and reward them for their endeavours 
- Hold meetings at frequent intervals to address problems and figure out solutions

- Always be an instructor and a student [21]

- Know when to fire an employee

\subsubsection{Communication}

Communication or Correspondence is most imperative for achieving the great name as an expert. Thinking from the patients' point of view and attempting to clarify in straightforward however non-phobic words about the method will help in building up the trust of patient for the specialist. This will likewise spare the legitimate ramifications if there should be an occurrence of adversity, which can emerge by not disclosing the intricacies appropriately to the patients. The way toward relieving a patient requires an allencompassing methodology, which includes contemplations post treating a malady. It warrants a few aptitudes in a specialist along with the specialized ability. Studies have showed great correspondence ability in a specialist improves patient's consistence and general fulfilment. There are fundamental standards of rehearsing great correspondence. Persistent tuning in, compassion, and focusing on the para verbal and non-verbal parts of the correspondence are the essential steps that are often disregarded. Appropriate data about the nature, course and forecast of the infection are essential. Additionally, patients and orderlies ought to be clarified about the need and yield of costly examinations and dangers/benefits engaged with obtrusive strategies. One ought to be mindful while overseeing troublesome experiences and breaking awful news. Formal preparation of the specialists in improving relational abilities is vital and has demonstrated to improve outcomes. Furthermore, it is additionally helpful in overseeing difficult clinical experiences. This way diminishes the disappointment of both the specialist and the patient or chaperon in circumstances of enthusiastic upheavals. It has also appeared to diminish work pressure and increase work fulfillment [22].

\subsubsection{Record Keeping}

Record keeping is vital to a successful practice especially in view of the legal implications that come along with a failure to maintain the same. One should maintain both a hard copy and a virtual copy of their records as backups are most essential. Informed consent forms should clearly record possible complications in a language understood by the patient. Photographic records at the preop, intraop, and postop phases need to be maintained and become especially important when a patient has unrealistic expectations. It is also important to maintain well-documented out-patient records and operative notes. Never forget the seventh principle of the Caldicott report, an NHS report on patient information, which says 'the duty to share information can be as important as the duty to protect patient confidentiality' [23].

\subsubsection{Reformulating the Strategy}

If at any point of time you come to realize that your practice is unable to achieve patient needs or financial goals, it is time to reconsider your strategy [16].

\subsubsection{Professional and Financial Growth in Career}

Nothing is permanent in life and in one's career. You can run your profession for a particular timeframe to be trailed by slow decrease in the training with age. Wellbeing and prosperity play a vital depiction to build the life span of the training (Fig. 43.4a). Till 45 years, there is a tendency to achieve followed by continuous decrease in the field. The thought is to augment the achievement with slow decrease. A specialist can viably work till the age 55-60, which can be expanded till 65-70 with great wellbeing and consistent learning. It is the duty of old specialists to offer approach to novel specialists for the improvement of field. Supportable model can be made to prepare novice specialists followed by naming them as partners.

\subsubsection{Time Management (Fig. 43.4b)}

Time is the most essential commodity that we have in our lives. Digitalization of many facets of hospital management has helped save time. This time can be re-invested in various other aspects of your clinical practice like discussion regarding treatment planning and discussion of various cases. Make sure you plan your day daily and weekly so that you are aware of the time that you have and be able to invest it wisely [24].

\subsubsection{Management of Finances (Fig. 43.4C)}

One must learn how to handle finances appropriately; unnecessary and exorbitant spending at the earlier stages is not a wise idea and can lead to a sudden financial crisis, which can even lead to the premature end of one's career. As mentioned before, expansion and modernization of the practice should follow a well-thought-out long-term incremental approach. Similarly, it is wise to slowly create an alternate source of income to help tide over any financial crises that one may face throughout the course of their career [25].

\subsection{Conclusion}

Oral and maxillofacial surgery is gaining popularity as a field and general awareness is increasing in India. It is the responsibility of new surgeons to contribute their best to the field in order to get the maximum out of their careers 
a

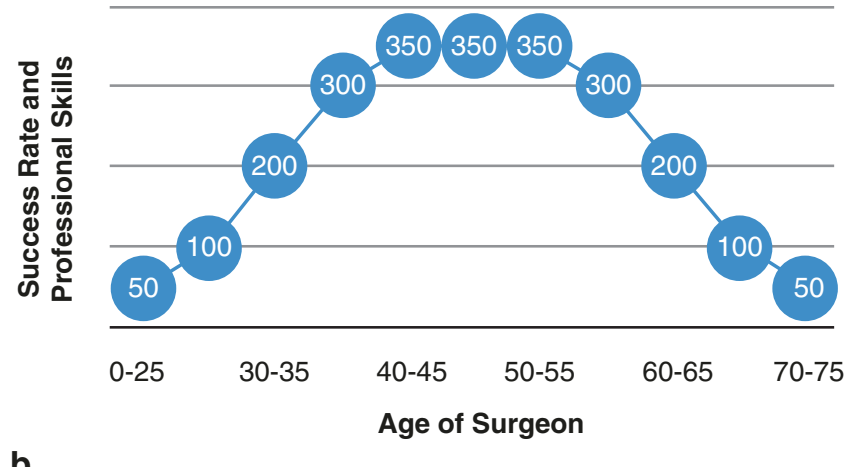

b

TIME FOR PRIMARY INCOME GENERATION

TIME FOR SECONDARY INCOME GENERATION

TIME FOR PERSONAL NEEDS

TIME FOR PASS TIME

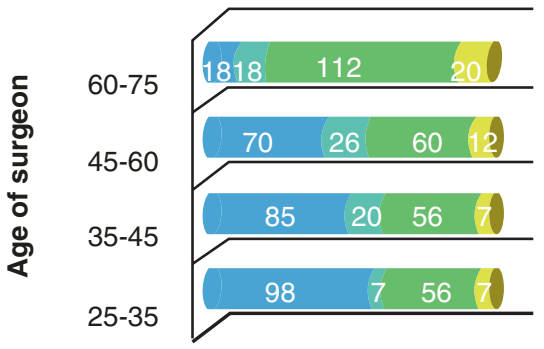

Number of hours in a week and time management

INCOME FROM PROFESSION

INCOME FROM INVESTMENT

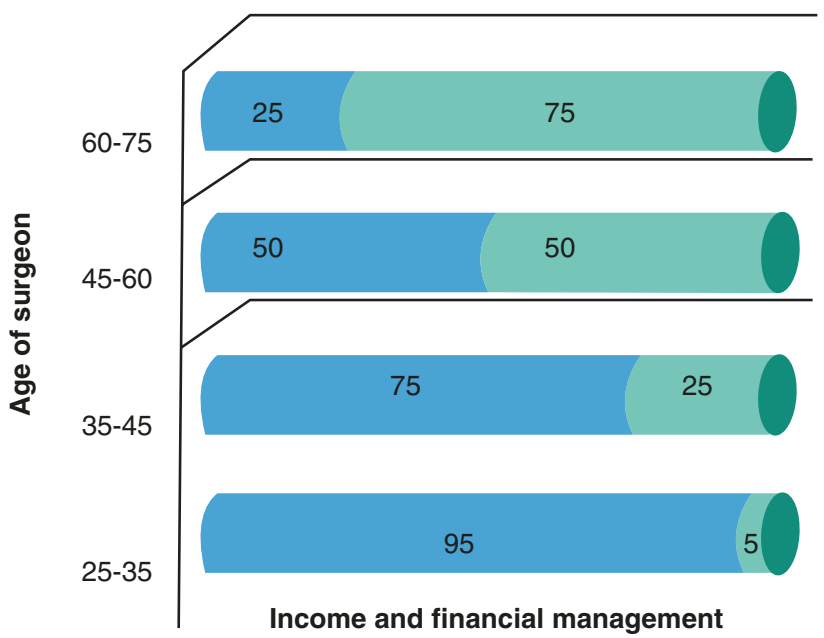

Fig. 43.4 (a) Professional life cycle of oral and maxillofacial surgeon. (b) Time management in the life of a maxillofacial surgeon. (c) Finances management in the life of a maxillofacial surgeon and life. As is said 'Do good and it will come back in unexpected ways to you'. Never lose your principles and ethics in this competitive world as it will only tarnish your reputation. Everyone has a specific purpose in this world. The aim is to find that purpose and work upon it with the help of the skills and knowledge you have gathered. These were my rules for success that I stumbled up on while achieving my goals. The newer generation is getting smarter and sharper and will surely contribute to a new set of rules and redefine success.

'Those are my principles, and if you don't like them, well, I have others'-Groucho Marx

Disclosure Authors have no financial conflicts to disclose.

\section{References}

1. Samman N. The modern specialty of oral and maxillofacial surgery. 2009;14(6). Dental Bulletin, The Hong Kong Times.

2. Kumar S. Training pathways in oral and maxillofacial surgery across the globe - a mini review. J Maxillofac Oral Surg. 2017;16(3):269-76.

3. Clark PK, Markiewicz MR, Bell RB, Dierks EJ. Trends and attitudes regarding head and neck oncologic surgery: a survey of United States oral and maxillofacial surgery programs. J Oral Maxillofac Surg. 2012;70:717-29.

4. Laskin DM. The past, present, and future of oral and maxillofacial surgery. J Oral Maxillofac Surg. 2008;66:1037-40.

5. Smith M. Aristotle and education. 2001. http://infed.org/mobi/ aristotle-and-education/

6. Sadideen H, et al. Surgical experts: born or made? Int J Surg. 2013;11:773-8.

7. Kolb DA. Experiential learning: experience as the source of learning and development, vol. 1. Englewood Cliffs, NJ: Prentice-Hall; 1984.

8. Knowles MS. The modern practice of adult education: Andragogy versus pedagogy (Revised edition). Prentice Hall/Cambridge: Englewood Cliffs; 1988.

9. Haider SM, et al. Oral \& maxillofacial surgery; A historical review of the development of the surgical discipline. Int J Surg. 2018.

10. Niamtu J. Beginning a new oral and maxillofacial surgery practice.

11. Walker TW, et al. Educational paper: research in oral and maxillofacial surgery. Br J Oral Maxillofac Surg. 2010;48(8):629-32.

12. Ghosh R, et al. Management and leadership skills for doctors. BMJ. 2008;336

13. McDonald $\mathrm{S}$, et al. Where to put an OMS practice, A supplement to the AAOMS. Today Newsletter. March/April 2007.

14. Pollock SL, et al. Financial arrangements in an oral and maxillofacial surgery practice, Part II, A supplement to the AAOMS. Today Newsletter. March/April 2009.

15. Miron-Shatz T, et al. Promoting business and entrepreneurial awareness in health care professionals: lessons from venture capital panels at Medicine 2.0 Conferences. J Med Internet Res. 2014;16(8):e184. 
16. Rodríguez Perera Fde P, et al. Strategic planning in healthcare organizations. Rev Esp Cardiol (Engl Ed). 2012;65(8):749-54. Epub 2012 Jun 13.

17. Watkins M. From SWOT to TOWS: answering a reader's strategy question. Harv Bus Rev. 2007;27.

18. Wiley Encyclopedia of management, SWOT analysis.

19. Weihrich H. The TOWS Matrix: A tool for situational analysis, Long range planning. 1982;15(2):54-66. https://doi.org/ 10.1016/0024-6301(82)90120-0.

20. Bhangale V. Marketing of healthcare services in India: a study on factors influencing patients' decision making on choice of a hospital. J Manag Market Healthcare. 2011;4(4).
21. Mamoon Z, et al. Hiring the right people for your organization. Glob J Manag Bus Res Admin Manag. 2013;13(8).

22. Ranjan $P$, et al. How can doctors improve their communication skills? J Clin Diagn Res. 2015;9(3):JE01-4.

23. Mathioudakis A, et al. How to keep good clinical records. Breathe (Sheff). 2016;12(4):369-73.

24. Christie $S$, et al. How to improve your time management skills. BMJ. 2012;344

25. Halvorson GC. Healthcare tipping points. Healthcare Financ Manag. 2005;74:80.

Open Access This chapter is licensed under the terms of the Creative Commons Attribution 4.0 International License (http://creativecommons. org/licenses/by/4.0/), which permits use, sharing, adaptation, distribution and reproduction in any medium or format, as long as you give appropriate credit to the original author(s) and the source, provide a link to the Creative Commons license and indicate if changes were made.

The images or other third party material in this chapter are included in the chapter's Creative Commons license, unless indicated otherwise in a credit line to the material. If material is not included in the chapter's Creative Commons license and your intended use is not permitted by statutory regulation or exceeds the permitted use, you will need to obtain permission directly from the copyright holder. 